\title{
Choice of Diet by Rats
}

\section{Choice of Diets Gontaining Various Members of the Vitamin B Complex}

\author{
By D. E. TRIBE* AND J. G. GORDON \\ Rowett Research Institute, Bucksburn, Aberdeenshire \\ (Received I I December 1954)
}

We have reported previously (Tribe \& Gordon, 1953) that rats deficient in the vitamin $\mathrm{B}$ complex showed a marked preference for a diet containing an adequate quantity of it over one deficient in these vitamins but otherwise identical. Rats not deficient in the vitamin B complex showed a similar but less obvious preference. The explanation is unknown; in the present state of our knowledge the suggestion of Harris, Clay, Hargreaves \& Ward (1933) that rats are able to associate a feeling of well-being with the consumption of a particular diet seems reasonable. The nature of this feeling, however, has never been demonstrated and, since in the earlier work it might have been associated with any one of seven different components of the vitamin $B$ complex, any conjecture as to its nature is necessarily tentative. For this reason we thought it worth while to investigate the behaviour of both deficient and non-deficient rats when allowed to choose between two diets differing in only one or two components of the vitamin B complex. Thus, by indicating for which components of the complex a deficient rat may show a preference it was hoped to provide information to assist future investigations into the nature of the postulated feeling of well-being.

EXPERIMENTAL

This experiment was designed in consultation with Dr J. W. Whitfield, Department of Psychology, University College, London.

Diets. The composition of the diets used is shown in Table I.

Table r. Composition of experimental diets

Diet 16

\begin{tabular}{|c|c|c|c|}
\hline Casein (vitamin-free) (g) & 230 & McCollum salts i $85(\mathrm{~g})$ & 50 \\
\hline Glucose (g) & 330 & Maize starch $(\mathrm{g})$ & 400 \\
\hline Margarine (g) & 150 & Radiostoleum (vitamins A and $\mathrm{D}$ ) (ml.) & 3 \\
\hline $\begin{array}{l}\text { Diet } 16 a=\operatorname{diet} 16 \text { with } 0 \\
\text { Diet } 16 b=\operatorname{diet} 16 a \text { with } \\
\text { Diet } 16 c=\operatorname{diet} 16 b \text { with } \\
\text { Diet } 16 d=\operatorname{diet} 16 c \text { with } \\
\text { Diet } 37=\operatorname{diet} 16 d \text { with } 10\end{array}$ & $\begin{array}{l}3 \mathrm{mg} \\
.3 \mathrm{mg} \\
3 \mathrm{mg} \\
.0 \mathrm{mg} \\
.0 \mathrm{mg}\end{array}$ & $\begin{array}{l}\mathrm{e} / \mathrm{l} 00 \mathrm{~g} \\
\text { xin hydrochloride/100 } \mathrm{g} \\
\text { vin/100 } \mathrm{g} \\
\text { a pantothenate and } 4.0 \mathrm{mg} \text { nicotinic acid } \\
\text { tol and } 10.0 \mathrm{mg} p \text {-aminobenzoic acid/100 }\end{array}$ & $\begin{array}{l}\mathrm{d} / \mathrm{r} 00 \mathrm{~g} \\
\circ \mathrm{g}\end{array}$ \\
\hline
\end{tabular}

Management of rats. Thirty-six hooded 'Lister' rats were divided into three groups in such a way that the groups were comparable in sex and litter-mate distribution. Although all groups initially had twelve rats each, one animal in each of groups

* Present address: School of Veterinary Science, University of Bristol. 
I and 3 died (as the result of an accident unconnected with the experiment), so that these groups had eleven rats each whereas group 2 had twelve. During a preliminary period the animals in group I were fed exclusively on diet 16 in order to make them deficient in the vitamin B complex before the experimental period began. During this time the rats of group 2 were fed on diet 37, but only in such limited quantities as to maintain their body-weights similar to those of group $\mathrm{x}$. The rats in group 3 were fed on diet 37 in unlimited amounts, until by the beginning of the experimental period they each weighed on an average $150 \mathrm{~g}$ more than animals in the other groups. All the animals were kept in individual cages measuring $10 \times 10 \times 5$ in., floored with a fine-mesh portable mat. During the experimental period each rat was offered 15 or $30 \mathrm{~g}$ of the appropriate diet daily, depending on its body-weight. The difference between this amount and the daily residue was taken as the amount consumed. Beneath the mesh floor of each cage was placed a sheet of paper to collect any food scattered, which seldom amounted to an appreciable quantity. All the feeding pots were identical in shape and colour; since Tribe \& Gordon (1953) had previously confirmed in experiments on choice of diets by rats that the position of the food in a cage may influence its selection, positions of the feeding pots in this experiment were altered at frequent but irregular intervals. All the animals were weighed daily and received tap water without stint. The experimental period lasted ${ }_{5} 5$ days, during which time the six different diets were offered to each rat in each possible combination of pairs. The order in which they were offered was as follows:

$\begin{array}{lccccc}\text { Day } \ldots & \text { 1 } & 2 & 3 & 4 & 5 \\ \text { Diet } & 16 \text { or } 16 a & 16 b \text { or } 16 c & 16 \text { or } 37 & 16 d \text { or } 16 a & 16 c \text { or } 37 \\ \text { Day } \ldots & 6 & 7 & 8 & 9 & 10 \\ \text { Diet } & 16 a \text { or } 16 b & 37 \text { or } 16 d & 16 a \text { or } 16 c & 16 b \text { or } 16 & 16 d \text { or } 16 c \\ \text { Day } \ldots & \text { I } & 12 & 13 & 14 & 15 \\ \text { Diet } & 16 a \text { or } 37 & 16 \text { or } 16 d & 37 \text { or } 16 b & 16 c \text { or } 16 & 16 d \text { or } 16 b\end{array}$

In this way the same diet was never offered on successive days.

\section{RESULTS AND DISCUSSION}

The results are summarized in Table 2 . This table gives for each group the average amount of each diet that was eaten under every choice situation.

The results have been statistically analysed by $\mathrm{Mr} \mathrm{M}$. J. R. Healy who treated the results for each rat separately as an experiment in balanced incomplete blocks (Yates, 1936). In this way the effects of day-to-day variations in total food consumption were removed. The resulting figures were adjusted to a zero mean for each rat and an analysis of variance then gave the results shown in Table 3. It is of some interest, that the estimated standard errors obtained in this way are remarkably consistent, the smaller value in group 2 being due to the extra rat in this group.

It may be concluded from these figures that all groups of rats departed markedly from random behaviour. In group $\mathrm{I}$ a general preference was shown for rations that had the greater content of B-vitamins. It will be observed, however, that the main choice was for diets containing thiamine (nos. $16 a-d$ and 37 ) in preference to diet 16 which did not contain thiamine, and for diets containing riboflavin (nos. $16 c$, I6d 
and 37 ) in preference to diets $I 6, I 6 a$ and $16 b$ which did not. In group 2 the same trend was shown but rather less obviously, whereas in group 3 there was little preference shown for any of the diets, except that no. I6 was disliked relative to the others.

Table 2. Mean daily amount ( $g /$ rat) of each diet consumed by rats in each group, in every choice situation

Choice of diets
16 or $16 a$
$16 b$ or 16
16 or 37
$16 d$ or $16 a$
$16 c$ or 37
$16 b$ or $16 a$
37 or $16 d$
$16 a$ or $16 c$
$16 b$ or 16
$16 d$ or $16 c$
$16 a$ or 37
16 or $16 d$
37 or $16 b$
$16 c$ or 16
$16 d$ or $16 b$

\begin{tabular}{|c|c|c|c|}
\hline \multicolumn{4}{|c|}{ Group no. } \\
\hline$\stackrel{\text { I }}{\text { Amount }}$ & $\stackrel{2}{2}$ & $\mathrm{Am}$ & bunt \\
\hline $2 \cdot 3 \quad 9 \cdot 3$ & $6.8 \quad 8.8$ & $5 \cdot 9$ & $8 \cdot 7$ \\
\hline $\begin{array}{ll} & 7 \\
4.7 & 7.8\end{array}$ & $5 \cdot 3 \quad 8 \cdot 2$ & $8 \cdot 3$ & $8 \cdot 8$ \\
\hline $4 \cdot 1 \quad 9 \cdot 7$ & $7.5 \quad 5 \cdot 2$ & $7 \cdot 7$ & $9 \cdot 3$ \\
\hline $8.2 \quad 7.2$ & $5.7 \quad 5.7$ & $6 \cdot 5$ & $9 \cdot 5$ \\
\hline $9 \cdot 0 \quad 6 \cdot 4$ & $6 \cdot 7 \quad 7 \cdot 1$ & $9 \cdot 4$ & 6.9 \\
\hline $9 \cdot 4 \quad 2 \cdot 9$ & $6 \cdot 2 \quad 4 \cdot 6$ & $7 \cdot 5$ & $4 \cdot 7$ \\
\hline $9 \cdot 9 \quad 5 \cdot 7$ & $10.9 \quad 5.4$ & $6 \cdot 9$ & $7 \cdot 3$ \\
\hline $\begin{array}{ll}3.9 & 9.8\end{array}$ & $\begin{array}{ll}4 \cdot 5 & 8 \cdot 2\end{array}$ & $6 \cdot 3$ & $8 \cdot 5$ \\
\hline $8.0 \quad 4.7$ & $\begin{array}{ll}5 \cdot 3 & 5 \cdot 8\end{array}$ & $8 \cdot 9$ & $4 \cdot 5$ \\
\hline II.O $6 \cdot \mathrm{I}$ & 13.1 & $9 \cdot 8$ & $6 \cdot \mathrm{I}$ \\
\hline $5.1 \quad 10 \cdot 0$ & 2.9 II. 3 & $7 \cdot 9$ & $6 \cdot I$ \\
\hline $2 \cdot 4 \quad 12 \cdot 4$ & $5.7 \quad 8.5$ & 6.5 & $8 \cdot 6$ \\
\hline 10.54 .6 & $12 \cdot 7 \quad 2 \cdot 8$ & $8 \cdot 6$ & $5 \cdot \mathrm{I}$ \\
\hline$I 2 \cdot 2 \quad 2 \cdot I$ & $\begin{array}{lll}\text { II } & 3.4\end{array}$ & $8 \cdot 5$ & 3.7 \\
\hline $12 \cdot 4 \quad 2 \cdot 3$ & $12 \cdot 3 \quad 2 \cdot 6$ & $9 \cdot 6$ & $6 \cdot 2$ \\
\hline
\end{tabular}

Table 3. Measures of preference indicated by relative food consumption $(\mathrm{g} / \text { day })^{*}$

\begin{tabular}{|c|c|c|c|c|c|c|}
\hline \multirow{2}{*}{$\begin{array}{c}\text { Group } \\
\text { no. }\end{array}$} & \multicolumn{6}{|c|}{ Diet no. } \\
\hline & 16 & ז6a & $16 b$ & $16 c$ & $16 d$ & 37 \\
\hline I & -5.98 & $-r \cdot 86$ & $-x \cdot 60$ & $2 \cdot 97$ & $3 \cdot 49$ & 2.98 \\
\hline 2 & $-1 \cdot 60$ & $-r \cdot 94$ & -3.54 & 0.64 & $2 \cdot 8 \mathrm{I}$ & $3 \cdot 62$ \\
\hline \multirow[t]{2}{*}{3} & $-2 \cdot 60$ & 0.43 & -0.04 & $\mathrm{x} \cdot 03$ & $r \cdot 09$ & 0.09 \\
\hline & \multicolumn{6}{|c|}{ * See text p. $20 \mathrm{r}$. } \\
\hline
\end{tabular}

Standard error of the mean

$\pm 0.69$

$\pm 0.65$ $\pm 0.70$

I. The food preferences of thirty-four 'Lister' rats, some of which had received diets deficient in the vitamin B complex, were examined in an experiment involving the use of six diets, which differed only in their contents of various members of the vitamin $\mathrm{B}$ complex.

2. The rats that had received diets deficient in the vitamin B complex showed a marked preference for diets containing thiamine and riboflavin. The behaviour of the other rats was similar but less marked.

The authors wish to thank $\mathrm{Mr} \mathrm{G}$. Porter and his staff for assistance in the management of the experimental animals, and Mr M. J. R. Healy for his statistical advice.

\section{REFERENCES}

Harris, L. J., Clay, J., Hargreaves, F. J. \& Ward, A. (1933). Proc. roy. Soc. B, II3, I61.

Tribe, D. E. \& Gordon, J. G. (1953). Brit. F. Nutr. 7, I97.

Yates, F. (1936). Ann. Eugen. 7, 121. 